\title{
"QUEM CONTA UM CONTO AUMENTA UM PONTO": PAPINI E AS ANTOLOGIAS
}

\begin{abstract}
Aline Fogaça dos Santos Reis e Silva *
RESUMO: O objetivo deste trabalho é refletir sobre a tradução e a recepção de alguns contos esparsos do escritor florentino Giovanni Papini nas seguintes antologias brasileiras: Obras-primas do conto moderno, Contos Italianos, Maravilhas do conto italiano, Maravilhas do conto fantástico, Maravilhas do conto bíblico e Contos e novelas de língua estrangeira.
\end{abstract}

PALAVRAS-CHAVE: Giovanni Papini; contos; tradução; recepção; antologias.

ABSTRACT: Obiettivo del presente articolo è riflettere sulla traduzione e la ricezione di alcuni racconti sparsi dello scrittore fiorentino Giovanni Papini, che si trovano nelle seguenti antologie brasiliane: Obras-primas do conto moderno, Contos Italianos, Maravilhas do conto italiano, Maravilhas do conto fantástico, Maravilhas do conto bíblico $e$ Contos e novelas de língua estrangeira.

PAROLE CHIAVE: Giovanni Papini; racconti; traduzione; ricezione; antologie.

ABSTRACT: The purpose of this paper is to reflect on the translation and on the critical reception of some scattered short stories of the Florentine writer Giovanni Papini in the following Brazilian anthologies: Obras-primas do conto moderno, Contos Italianos, Maravilhas do conto italiano, Maravilhas do conto fantástico, Maravilhas do conto bíblico and Contos e novelas de língua estrangeira.

KEYWORDS: Giovanni Papini; short stories; translation; critical reception; anthologies.

* Universidade de São Paulo, São Paulo (Brasil) - aline.fogaca@yahoo.com.br

Processo n.2013/20971-0 Fundação de Amparo à Pesquisa do Estado de São Paulo (FAPESP)

DOI: http://dx.doi.org/10.11606/issn.2238-8281.v0i34p64-76 


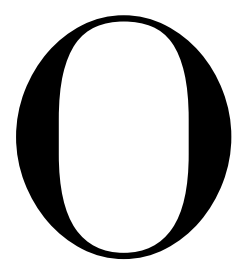

exame da recepção e repercussão do escritor florentino Giovanni Papini (1881-1956) no Brasil dá-se pelos títulos integrais traduzidos, entre os quais, Um homem acabado $(1923)^{1}$, Palavras e sangue $(1934)^{2}$, As testemunhas da paixão $(1950)^{3}$, entre outros; mas igualmente por meio da fortuna crítica presente em notas, resenhas, crônicas e artigos publicados em alguns dos principais periódicos nacionais. Além desses, outra forma de recepção são as publicações de alguns contos em antologias, mapeadas durante a segunda fase do projeto Literatura Italiana Traduzida no Brasil ${ }^{4}$. São os volumes: Obras-primas do conto moderno (1951), da Livraria Martins Editora; Contos Italianos (s/d), publicado pela Edigraf; Maravilhas do conto italiano (1959), Maravilhas do conto fantástico (1958) e Maravilhas do conto bíblico (1960), pela Cultrix; e Contos e novelas de língua estrangeira (1963), pela Logos.

Obras-primas do conto moderno é organizada por Almiro Rolmes Barbosa e Edgard

1 Publicado pela editora A. Tisi \& Cia., sem informação do tradutor.

2 Traduzido por Mário Quintana e publicado pela editora Livraria do Globo.

3 Traduzido por Nair Lacerda e publicado pela editora Saraiva.

4 Resultado da colaboração entre pesquisadores da USP e UFSC. Em sua primeira fase, entre 2010 e 2013, sob a coordenação das professoras doutoras Lucia Wataghin (USP) e Patricia Peterle (UFSC) e do professor doutor Andrea Santurbano (UFSC), recebeu apoio do CNPq (Edital Ciências Humanas, processo n. 400500/2010-8). Já sua segunda fase, de 2014 a 2016, contou com o apoio da FAPESP e a inclusão de três novos coordenadores: prof. ${ }^{\text {a }}$ Dr. ${ }^{\text {a }}$ Silvana de Gaspari (UFSC), prof. Dr. Fernando Modesto (USP) e o Dr. Francisco Degani. 
Cavalheiro, e traz os desenhos de Armando Pacheco para os retratos dos escritores selecionados. É uma antologia bem acurada, e não somente pelos aspectos relativos à formatação e pela experiência tanto da editora quanto dos organizadores, mas também pela escolha criteriosa dos nomes a serem aproximados ao público. Como está descrito já no texto da chamada "orelha" do livro, a intenção era a de gerar uma visão ampla sobre a evolução do conto nas letras estrangeiras e nacionais.

A crítica é um fator determinante para a construção do reconhecimento do valor da coletânea. E nesse sentido, Antonio Candido dedica-lhe o ensaio crítico "Contos", no qual tal obra serve de mote para as suas ponderações acerca do gênero:

$\mathrm{Na}$ antologia recente dos Srs. Edgard Cavalheiro e Almiro Rolmes Barbosa, a propósito da qual faço estas reflexões, encontramos mais os artistas do que os meticulosos. Encontramos, também e talvez sobretudo, os contadores, que encaram o conto segundo uma concepção mais próxima da popular, como contação de histórias. O que os inclui entre os estetas, inclinados a ver na narrativa apenas a sua própria beleza, e não o conteúdo ou as implicações que possa ter. (CANDIDO, 2000, p. 184)

Segundo ainda a reflexão de Candido, Papini estaria inserido na categoria dos meticulosos, cuja característica é procurar no conto "uma forma de expressão rara, um instrumento quase experimental de pesquisa literária” (CANDIDO, 2000, p. 184). Ao lado dele, acrescenta grandes personalidades da literatura, como Conrad e Joyce.

Bruna Becherucci também dedicará uma breve resenha a esta antologia, publicada n'O Estado de S. Paulo em $1^{\circ}$ de maio de 1967, na qual elenca as escolhas felizes e infelizes de Barbosa e Cavalheiro na seleção dos contos integrantes do volume. A respeito de Papini, ela diz que: "é moderna, quase uma antecipação de certas atitudes de nossa época mais recente, a raivosa inconformação de Papini em seu originalíssimo 'Quatro cães fizeram justiça '5"' (BECHERUCCI, 1967, p. 1).

O conto em questão é uma publicação inédita na obra Parole e Sangue (1912), na qual foram reunidos alguns contos inéditos a outros que já haviam sido publicados anteriormente em revistas italianas.

5 Em italiano: "Quattro cani fecero giustizia”. 
Na perspectiva da crítica italiana, esses contos vêm categorizados como novelas, fato que talvez possa ser explicado em razão da elaboração de sua narrativa e de seu enredo (BONATO, 2012, p. 81). Nesse período, Papini ganha considerável renome pela série de novelas que publica: além de Parole e Sangue, há Il pilota cieco (1907) e Il tragico quotidiano (1906), com as quais o autor declara ter formado sua obra como narrador. Do confronto entre elas, pode-se concluir que enquanto as últimas privilegiam a fantasia, a primeira retoma a narrativa mais próxima à realidade ou a um realismo formal. O excerto abaixo, extraído da tradução do conto, demonstra a existência de uma narração intrincada, na qual se mesclam as descrições do ambiente com o estado psicológico do narrador-personagem:

- Daqui - dizia com ar de triunfo mr. Dayson - se avista tôda a Toscana Vallombrosa, Pisa, ali os montes Apuani, mais além Mugello e Valdorno e um pouco de Casentino - tôda a Toscana!

Não se via nada - só maciços perfis, negros através da névoa e da escuridão, mas eu via o mesmo; via a minha terra divina com seus rios de prata e suas casas côr de sol e seus montes azuis adornados de ciprestes - tôda a minha terra aos pés daquele intruso filantropo barbudo. Não, não e não - meu coração dizia. Mas em tôrno de mim tudo estava escuro e frio. Nenhuma voz contestava a minha raiva. Onde estavam os senhores dêste país? Nenhum protestava? (PAPINI, 1951, p. 255)

A paisagem toscana alude imediatamente à naturalidade de Papini, Florença, e nesse sentido permite as considerações a respeito de outra obra publicada contemporaneamente a Palavras $e$ sangue e igualmente importante para o entendimento da mudança de foco na narrativa papiniana: Un uomo finito (1912). Em ambas, o retorno à campagna - termo italiano para o qual podem ser atribuídas múltiplas significações, mas sempre ligado ao campo, à natureza -, parece ser a resposta ao homem que procura uma existência mais serena; assim como defendiam os poetas árcades, com o seu lema fugere urbem.

Outro exemplo mais explícito da narrativa mesclada, em que inclusive percebe-se o uso da ironia no tratamento dado à metafísica e à filosofia:

Vogava-se na mais alta metafísica; no entanto, a chegada de um grande pastel de chocolate interrompeu um absurdo paralelo entre Platão e Aristóteles. De repente, 
mr. Dayson deixou a filosofia. Estávamos no final da comida e das garrafas - o momento orgíaco do vil otimismo filisteu. (PAPINI, 1951, p. 255)

Vê-se que não é um ataque às ciências, mas à verborragia utilizada pelo personagem mr. Dayson, com o qual o narrador-personagem demonstra-se incomodado através de um sentimento de raiva e desprezo.

Mais contos de Parole e sangue estão presentes nas outras antologias elencadas, como é o caso de Contos italianos, organizada pelo professor Jacob Penteado. $\mathrm{O}$ autor introduz o volume com um panorama breve dos principais movimentos estéticos da história da literatura italiana, explicando as idas e vindas do gênero conto. A síntese, para além do seu caráter didático, tem o escopo de justificar aos leitores a heterogeneidade da seleção dos escritores e das temáticas.

No tocante a Papini, o conto escolhido foi "Esperança"' que, assim como "Quatro cães fizeram justiça", era inédito até a sua publicação em Parole e Sangue.

A característica mais marcante de "Esperança" é o círculo metanarrativo, no qual a personagem homônima, escritora, apercebe-se de si mesma em meio a concretização dos eventos narrados em seus contos:

[...] A literatura é um espelho. Fazemos agir os outros, mas não nos conhecemos e acabamos por representar somente a nós mesmo. Quando muito, o que há de estranho nisso é a senhora não o ter percebido antes.

- Espere - disse com fôrça a Senhorita Esperança, meio encabulada - espere que lhe conte o resto. A história não termina aqui. O senhor acredita-me, também, mais tôla do que o sou de verdade. $\mathrm{O}$ fato realmente bizarro vem depois. Quando escrevo as histórias da mulher que se me assemelha, acontece que as mesmas aventuras, imaginadas por mim para a imaginária heroína, repetem-se na vida de mim mesma, exatamente comigo, em carne e osso. (PAPINI, s/d, p. 156, grifo do autor)

Nesse processo, torna-se tênue a divisão entre o real e o imaginário, e o leitor assume uma nova função além daquela da leitura: ele é também uma testemunha.

6 Em italiano: "Speranza". 
O caráter dual do conto invoca o tema do duplo literário, abordado sob a perspectiva da literatura fantástica, assim como o é em O retrato de Dorian Gray (1891), de Oscar Wilde.

Maravilhas do conto italiano é organizada por Diaulas Riedel e Aldo Bagnotti, com introdução e notas de Edgard Cavalheiro, o qual, para cada autor selecionado, traçou um breve panorama de sua trajetória literária. Junto a essa breve biografia, há também uma ilustração dos escritores, de autoria de D. Nasi. Por fim, fazendo menção à tradição italiana de novelas e contos, iniciada com Boccaccio, o paratexto presente na "orelha" assegura aos leitores um percurso pelas diferentes fases da ficção na Itália.

Nesta antologia, a temática da contemplação do retrato como o espelho da alma também está presente no conto "O retrato profético"7 , publicado primeiramente na revista Riviera Ligure em março de 1912, e, depois, reeditado em Palavras e sangue. Nele é possível identificar a intertextualidade com as obras de Oscar Wilde e Nathaniel Hawthorne (BONATO, 2013, p. 94), bem como com "O retrato oval", de Edgar Allan Poe:

A tela não estava inteiramente coberta de tinta. Olhando-se de alguma distância distinguia-se ao centro uma cara que certamente não era minha. [...]

- Que lhe parece? - perguntou Hartling, sorrindo satisfeito - não lhe parece minha pintura mais original? Não tentei pintar o seu rosto, mas quis colher o momento do seu espírito para tôda a eternidade.

Perdi tempo para observar melhor. Por fim, depois de olhá-lo por todos os lados e de tôdas as distâncias, me convenci de que nunca tinha visto uma coisa mais grotesca. (PAPINI, 1959, p. 200-201)

Na paixão do narrador-personagem que será retratado reside o narcisismo em observar sua própria face sob diferentes ângulos e perspectivas. Entre os seus muitos retratos, há um em particular, feito por Hartling, com o qual se decepciona, por não compreender o quão perene se demonstra a sua arte pictórica: mais do que a reprodução de uma fisionomia, o artista buscava emoldurar a sua essência, sua alma. Passado o choque do primeiro contato, alguns anos depois, o personagem narcisista resolve comprar o quadro, e se surpreende com a "nova" imagem confrontada:

7 Em italiano: "Il ritratto profetico". 
Abri a caixa e pus o retrato no chão apoiado contra o muro, sob um grande espelho. Qual foi o meu estupor, quando vi que o retrato agora se parecia comigo! [...] Aquêle retrato, que seis anos atrás era um (sic) imunda caricatura, converterase em meu retrato precioso e profundo. Hartling tinha visto o meu $e u$ futuro, de seis anos depois, e o tinha pintado. (PAPINI, 1959, p. 202-203)

Diferentemente do que ocorre em Wilde, em que apenas o retrato envelhece, enquanto o seu "dono" mantém a juventude, em Papini, a antecipação das marcas do tempo fere a vaidade do personagem que somente as compreende quando o seu retrato, de fato, reflete os traços e a maturidade adquiridos.

A respeito da divulgação deste volume, a Folha da Manhã de 21 de dezembro de 1957 traz uma propaganda sobre o seu lançamento, na qual diz que a antologia faz parte de uma coleção idealizada pela editora Cultrix, "Maravilhas do conto universal", que contou com aproximadamente dez volumes.

Entre eles, temos também Maravilhas do conto fantástico, organizada por Fernando Correia da Silva, com seleção e introdução de José Paulo Paes. No prefácio, Paes explica que o conto fantástico é herdeiro do legado da novela gótica, cujo maior representante é o conde e escritor Horace Walpole. Além disso, alerta o leitor sobre o fato de que encontrará diferentes tipos de narrativa fantástica: dos profissionais até os amadores.

Giovanni Papini, segundo o crítico, está elencado no primeiro grupo, ao lado de Miguel de Unamuno, Guillaume Apollinaire, entre outros das letras estrangeiras; e, no caso das nacionais, está ao lado de Carlos Drummond de Andrade, Aluísio Azevedo e Álvares de Azevedo.

O conto papiniano selecionado é "História completamente absurda", que havia sido publicado na já citada Riviera Ligure, em dezembro de 1906, e reeditado na obra Il pilota cieco. Sua temática, assim como a dos outros contos mencionados anteriormente, abarca a questão do duplo, enquanto dupla personalidade, alter ego do protagonista, desdobramento entre espírito e corpo (BONATO, 2013, p. 58-59), como se pode verificar nesta passagem:

Mas a razão do meu desconcêrto era bem forte: a história que êsse homem lera era a narrativa completa e precisa de tôda a minha vida íntima e exterior. [...]

8 Em italiano: "Storia completamente assurda". 
Minha confusão e meu pavor vinham dessa exatidão impecável, dessa inquietante escrupulosidade. Eu nunca havia visto aquêle homem e êle afirmava não conhecerme. (PAPINI, 1958, p. 235-236)

O homem descrito pelo narrador é quem um dia lhe bateu à porta, entrou em sua casa e iniciou a leitura de uma história imaginada, mas que, na verdade, referia-se à sua vida. É, também, o seu duplo, mas através do qual busca a morte por meio do aniquilamento da compreensão e da confissão:

- Perdoe-me se minha leitura o fatigou. Creio que nunca mais voltarei a incomodar pessoa alguma. Esqueça-me o mais breve possível.

$\mathrm{Na}$ verdade, essas foram as suas últimas palavras, pois que, galgando agilmente o parapeito, jogou-se com um rápido impulso ao rio, sem abandonar a valise. [...] Apenas entrei em meu quarto, estendi-me no leito e adormeci imediatamente, abatido e humilhado pelo inexplicável.

Esta manhã despertei muito tarde e com uma estranha impressão. Parece-me estar já morto e aguardando apenas que venham sepultar-me. Sinto que pertenço a outro mundo e que tudo quanto me circunda tem um ar indizível de coisa passada, concluída, sem mais nenhum interêsse para mim. (PAPINI, 1958, p. 238, grifo do autor)

A respeito da temática da morte e do tom negativo presentes em Il pilota cieco, Italo Calvino pondera:

Volendo segnare il momento in cui il racconto fantastico italiano si stacca dai modelli ottocenteschi e diventa un'altra cosa (o cento altre cose) potremmo indicare il 1907, data del Pilota cieco, quel Papini giovanile caro a Borges, tutto esattezza e negatività, così diverso dal Papini che abbiamo conosciuto poi. (CALVINO apud BONATO, 2013, p. 58)

O Papini posterior é, sobretudo, o da temática religiosa, presente em obras como I testimoni 
della passione (1937), da qual foi extraído o conto "O cireneu", para compor a antologia Maravilhas do conto bíblico, organizada novamente por Fernando Correia da Silva, com seleção e introdução de Araújo Nabuco.

O conto em questão traz uma narrativa a respeito da vida de Simão de Cirene. É permeado por um caráter didático-religioso, e muito semelhante às fábulas no que concerne à lição moralizante contida em seu desfecho trágico, cuja tragicidade é uma espécie de castigo à presunção e vaidade do protagonista ao vangloriar-se de seu feito.

A respeito da repercussão desses volumes, a Folha da Manhã de 18 de janeiro de 1959 traz uma nota sobre Maravilhas do conto fantástico na seção "Livros novos", em que se recupera um pouco do tom presente no prefácio da antologia. Já em relação ao outro volume e a toda a coleção da Editora Cultrix, novamente a Folha da Manhã de 21 de setembro de 1958 apresenta mais uma propaganda.

A última coletânea elencada é Contos e novelas de língua estrangeira (1963), com organização e tradução da prof. a Yolanda Lhullier dos Santos e de Claudia Santos, cuja seleção de contos oscila entre um viés religioso e a morbidez. O escritor italiano participa com três contos: "O demônio me disse", "O demônio tentado" e "O verdadeiro cristão". ${ }^{10}$

O primeiro conto foi originalmente publicado na revista Il Campo, em 1905 e, posteriormente, republicado em Il tragico quotidiano, junto a outros contos inéditos, entre os quais, "Il demonio tentato". Terá ainda uma nova publicação em 1954 no volume Strane storie (BONATO, 2013, p. $29 ; 137) .{ }^{11}$

Diferentemente do que ocorre em "O cireneu", escrito quando Papini já havia se convertido ao catolicismo, em "O demônio me disse", o diálogo com o diabo, ao abordar o pecado original, levanta o tema do desejo humano de onipotência:

O homem, naquele jardim longínquo, perdeu pois, uma magnífica oportunidade para converter-se em Deus e eu perdi uma das poucas probabilidades de voltar ao céu. Mas eu creio, excelente amigo, e lhe digo, embora Você e os outros

9 Em italiano: "Simone di Cirene".

10 Em italiano, respectivamente: "Il demonio mi disse", "Il demonio tentato" e "Il vero cristiano".

11 De acordo com Bonato (2013, p. 137-138), a publicação da antologia Strane storie foi proposta a Papini pelo editor Vallecchi, com o objetivo de selecionar as novelas mais representativas de sua produção juvenil. O escritor, então, optou por extrai-las das obras Il tragico quotidiano (1906), Il pilota cieco (1913), Parole e sangue (1912) e Buffonate (1914). 
homens não dêem muito crédito aos conselhos do Demônio, eu creio que vós ainda estais em tempo de acabar com todos os frutos da árvore, estais em tempo de converter-vos em deuses. (PAPINI, 1963, p. 125, grifo do autor)

O ideal de tornar-se semelhante a Deus ou, como pontua o Demônio, tornar-se deuses, aproxima-se ao conceito da vontade de potência de Nietzsche (2011), assim como a experiência do escritor com o pragmatismo como vem descrito em suas ponderações em Sul Pragmatismo (1903 a 1911):

Nel mio pensiero, dal 1903 a oggi, sono stati sempre fermi alcuni punti che sono poi il succo del Pragmatismo: cacciata dei problemi senza senso e delle frasi vaghe - studio e riforma degli strumenti del pensiero - tendenza al particolare e al pluralismo piuttosto che all'universale e al monismo - aspirazione a una maggiore potenza della volontà e ad una efficacia diretta dello spirito sulle cose. Queste idee si ritrovano nei primi articoli del "Leonardo", in tutti quelli compresi in questo libro, nella conclusione teorica del mio Crepusculo dei Filosofi e perfino, sotto forma più artistica, nelle mie novelle e nell'Uomo finito. (PAPINI, 2000, p. 8-9).

Tal concepção era já um projeto presente em Un uomo finito, obra autobiográfica de Papini, permeada pelo tema do super-homem, que também remete a Nietzsche (2011). Além disso, demonstra o desejo do escritor pelo conhecimento infinito sobre a literatura (BONATO, 2013, p. 52).

Esse ideal ainda repercutirá no conto seguinte da mesma antologia, "O demônio tentado", novamente no diálogo entre o narrador e o demônio que o vem visitar durante a noite:

Mestre e amigo: chegou para ti o dia da tentação. Tu já não és capaz de tentar aos homens e sucede que os homens vêm tentar-te. Conseguiste-o com Adão, fracassaste com Cristo; mas não és nem homem nem Deus e eu sou um homem que se vai convertendo em Deus. Por isso tenho o direito e a fôrça de induzir-te em tentação e vingar a Adão e a seus filhos.

$\mathrm{Tu}$ ofereceste aos primeiros homens a divindade, a Cristo o reino da terra, a Fausto o poder. Mas eu te ofereço algo melhor, eu te ofereço não converter-te em um arremêdo de Deus, não que possuas o que existe, mas proponho fazer-te o verdadeiro inimigo de Deus, o definitivo destruidor do ser. (PAPINI, 1963, p. 128) 
Referindo-se até à desilusão de Fausto, diferentemente do usual, o homem tenta ao diabo, ao mesmo tempo em que lhe mostra os pontos em que fracassou. A resposta para a sua falência é o poder de aniquilação que está dentro do homem, do mal que possui em si, a ponto de corromper, mas não de ser corrompido.

O escritor, desde então, já estava questionando o dogma sobre o castigo eterno que seria dado à corrupção de Satanás, pois acreditava que a compaixão divina poderia conceder-lhe a redenção. Por essa razão, quando da publicação de Il Diavolo (1953), Papini insere como apêndice o conto "Il demonio tentato" (BONATO, 2013, p. 40). Isso também porque nessa obra a sua releitura do apocalipse será recorrente, gerando muitas polêmicas junto à cúpula do Vaticano.

Para concluir a análise da antologia, o último conto, "O verdadeiro cristão", também foi publicado em Parole e sangue e, posteriormente, selecionado para a antologia Strane storie. A narrativa, embora traga, de início, a descrição de Frei Angelo, que não era um sacerdote à antiga, mas um que "cheirava a Modernismo" (PAPINI, 1963, p. 134), na verdade discorre acerca do protagonista que dá título ao conto, mas que não é nomeado na trama. O "verdadeiro cristão", portanto, procura Frei Angelo na esperança de obter respostas para a sua angústia de como ser um legítimo seguidor de Cristo. Contudo, nem mesmo o frei é capaz de lhe ajudar, pois "mais do que em Deus, cria no poder da fé em Deus; mais do que em Cristo, cria na bondade dos que crêem em Cristo" (PAPINI, 1963, p. 134).

A atitude omissa do frei revela uma crítica de Papini ao intelectualismo estéril (BONATO, 2013, p. 107), reforçada, sobretudo, pelo modo como descreve os hábitos de estudo do religioso:

[...] frei Angelo, como de costume, encontrava-se sentado na cama e tinha diante de si cinco ou seis volumes encadernados em couro escuro, roídos e abertos de bôca para baixo. Era âquele o modo de ler do douto cônego; não era desses que se contentam com um só livro cada vez. Uma página ou duas de um e logo um capítulo de outro e logo um parágrafo de um terceiro, para voltar finalmente ao primeiro. Assim como somos capazes de seguir, dizia, uma conversação com cinco ou seis pessoas, sob a condição de que falem uma depois da outro (sic), assim não há tampouco nenhuma confusão em ler numa mesma hora cinco ou seis volumes e há a vantagem de poder retroceder para encontrar o fio perdido.

(PAPINI, 1963, p. 135) 
Por meio desta breve análise, vê-se que Papini, portanto, era um nome recorrente em antologias, desde as de contos de literatura fantástica até as de contos bíblicos. Nota-se que, embora algumas edições sejam mais bem estruturadas que outras, a ausência de informações sobre os tradutores é praticamente unânime. Nesse sentido, torna-se difícil afirmar se os contos selecionados foram extraídos de traduções publicadas nos anos anteriores ou se são novas traduções. E sob esse viés, vemos o quanto o ofício do tradutor, por mais que tivesse recebido uma valorização mais efetiva a partir dos anos 1930, durante o boom da tradução no Brasil, ainda permanecia à margem no confronto com outras funções da editoração.

Outro aspecto relevante refere-se à maior ou menor repercussão das coletâneas junto à mídia jornalística, veículo que à época talvez ocupasse o lugar de maior importância para a divulgação de um autor ou volume bibliográfico. Nas palavras de John Milton, "a coleção também classificou os autores de modo diferente do convencional, e ajudou a planejar a recepção do leitor e organizar suas expectativas em relação ao texto" (MILTON, 2010, p. 91).

\section{Referências:}

BECHERUCCI, Bruna. Obras-primas do conto moderno. In Suplemento feminino, São Paulo: XIV, (706): 1, maio 1967. http://acervo.estadao.com.br/pagina/\#!/19670507-28239-nac-0141-fem-1-not/busca/ Papini. Acesso: 14 out. 2016.

BONATO, Silvia. Le strane storie di Giovanni Papini, 2012/2013, 173 f. Tesi di Laurea (Filologia e Literatura Italiana). Veneza: Università Ca' Foscari, 2012/2013.

CANDIDO, Antonio. Contos. In Literatura e Sociedade, São Paulo: (5): 182-185, 2000. Folha da Manhã, Assuntos culturais, São Paulo: XXXIV, (10.655): 4, 18 jan. 1959. http://acervo.folha.uol.com.br/ fdm/1959/01/18/1/. Acesso: 14 out. 2016.

Folha da Manhã, Assuntos culturais, São Paulo: XXXIV,(10.555): 3, 21 set. 1958. http://acervo.folha. uol.com.br/fdm/1958/09/21/1/. Acesso: 14 out. 2016.

Folha da Manhã, São Paulo: XXXIII, (10.325): 9, 21 dez. 1957. http://acervo.folha.uol.com.br/ fdm/1957/12/21/1/. Acesso: 21/09/2016.

MILTON, John. A importância de fatores econômicos na publicação de traduções: um exemplo do Brasil. In Tradterm, São Paulo: 17: 85-100, 2010.

NIETZSCHE, Friedrich. Vontade de potência. Trad. Mário Ferreira dos Santos. Petrópolis: Vozes, 2011. (Textos Filosóficos)

PAPINI, Giovanni. Sul Pragmatismo. In Opere: dal Leonardo al Futurismo. Introdução e 
organização de Luigi Baldacci com colaboração de Giuseppe Nicoletti. 6. ed. Milano: Mondadori, 2000. p. 3-130.

O demônio me disse. In SANTOS, Yolanda Lhullier; SANTOS, Claudia (org. e trad.). Contos e novelas de língua estrangeira. 11. ed. São Paulo: Logos, 1963. p. 121-125. (Antologia da Literatura Mundial, 2)

. O demônio tentado. In SANTOS, Yolanda Lhullier; SANTOS, Claudia (org. e trad.). Contos e novelas de língua estrangeira. 11. ed. São Paulo: Logos, 1963. p. 127-131. (Antologia da Literatura Mundial, 2)

O verdadeiro cristão. In SANTOS, Yolanda Lhullier; SANTOS, Claudia (org. e trad.). Contos e novelas de língua estrangeira. 11. ed. São Paulo: Logos, 1963. p. 133-144. (Antologia da Literatura Mundial, 2)

. O cireneu. In NABUCO, Araújo; SILVA, Fernando Correa da (org.). Maravilhas do conto bíblico. São Paulo: Cultrix, 1960.p. 209-220. (Maravilhas do conto universal)

O retrato profético. In CAVALHEIRO, Edgard; RIEDEL, Diaulas; BAGNOTTI, Aldo C. (org.). Maravilhas do conto italiano. São Paulo: Cultrix, 1959, p. 197-204.

História completamente absurda. In PAES, José Paulo; SILVA, Fernando C. da (org.). Maravilhas do conto fantástico. São Paulo: Cultrix, 1958, p. 233-238.

Quatro cães fizeram justiça. In BARBOSA, Almiro R.; CAVALHEIRO, Edgard (org.). Obrasprimas do conto moderno. São Paulo: Livraria Martins Editora, 1951, p. 249-258.

. Esperança. In PENTEADO, Jacob (org.). Contos italianos. São Paulo: Edigraf, s/d. p. 153-159. (Primores do Conto Universal).

WATAGHIN, Lucia. Traduzioni brasiliane della letteratura italiana del Novecento: uno sguardo sulle antologie. In Interazioni linguistiche, letterarie e culturali tra l'Italia e i paesi d'oltralpe dal Quattrocento al Novecento. In GUARAGNELLA, Pasquale; LUISI, Francesco; MUSARRA, Franco (org.). Firenze: Franco Cesati, Editore, 2016, p. 215-223.

Recebido em 03/03/2017

Aprovado em 03/07/2017 